hinder his systematic studies on the flora, and his publication record during this period is most impressive. He had certain preferences, and the family Papaveraceae with the closely associated Fumariaceae engaged much of his attention. Other groups to which he had a predilection were the Scrophulariaceae, Labiatae and Leguminosae. Economic crops also interested him and he made notable contributions on Indian hemp, wheat, the mustards and pulses, and on the species of indigo.

Prain was appointed director of the Royal Botanic Gardens, Kew, on December 15, 1905. He took up his duties at a very difficult period when there was considerable discontent among the staff and much criticism about the state of the Kew publications. Before long he had eased the publication position and won the respect and esteem of his colleagues. As director he soon became immersed in committee work which, alas, is concomitant with the tenure of such responsible office. In spite of his considerable administrative load, Prain applied himself unsparingly to the continuation of his scientific work, and in this he was assisted by wise delegation of duties. $\mathrm{He}$ was not a familiar figure in the Gardens, preferring to be guided on horticultural matters by his able curatorial assistants. When he retired in 1922 the staff recorded their thanks "for his consummate tact and patience through years of unparalleled difficulty".

Naturally, with his distinguished record, many honours came his way. He was elected a Fellow of the Royal Society in 1905, president of the Botany Section of the British Association in 1909, president of the South-Eastern Union of Natural History Societies in 1912, and president of the Linnean Society in 1916. He was knighted in 1912 and was also honoured by the King of Sweden and the King of the Belgians. He received the degree of LL.D. from St. Andrews in 1911 and was awarded the Victoria Medal of Honour of the Royal Horticultural Society in 1912 and the Linnean Society's Gold Medal in 1935 .

Though on retirement Prain shed his heavy administrative duties and many of the advisory responsibilities linked with the directorship, he readily assumed fresh and important obligations; some, such as membership of the Council of the Zoological Society and appointment as a trustee of the British Museum, seemed somewhat outside his normal interests, but these offices were a tribute to his sound judgment and understanding. The two World Wars dealt harshly with Prain. In the first his only son was killed near Armentières and in the second his home in the Caterham valley was so badly damaged by bombs as to become uninhabitable. After the death of his wife in 1942, his health declined and his appearances in London becarne rarer. He died on March 16, 1944 (see Nature, 153, 426 ; 1944). Sir David Prain is still remembered with affection and gratitude by some of his former colleagues, happily still working at Kew.

\title{
THE NEW RADIO RESEARCH STATION, DITTON PARK, SLOUGH
}

\author{
By DR. R. L. SMITH-ROSE, C.B.E. \\ Director
}

\begin{abstract}
$\mathrm{O}^{\mathrm{N}}$ June 20, in the presence of a distinguished company, the new and permanent buildings of the Radio Research Station, at Ditton Park, Slough, Buckinghamshire, were opened by Sir Edward Appleton, principal and vice-chancellor of the University of Edinburgh. It was very appropriate that this ceremony should be performed by Sir Edward ; first, because he has been very closely associated with the programme of the Radio Research Board for some thirty-six years ; and secondly, because it was during his term of office as secretary of the Department of Scientific and Industrial Research that the post-war plans of the Department were drawn up. Among these plans was one which provided for the establishment of a Radio Research Organization which was to absorb and expand the work previously conducted in the Radio Division of the National Physical Laboratory. The plans being followed for this development, and a view of a model of the new building now formally opened, have been described in Nature $(175,921$; 1955). The present contribution reviews briefly the historical development of the Radio Research Station, and summarizes its present national programme of research as a prominent part of a wider, international range of activities.
\end{abstract}

\section{Historical}

It was realized at the outset that the new organization would require a large area of ground on which to erect its aerial systems and conduct experimental work, in addition to the provision of suitable laboratory buildings for development work and certain types of investigation and measurements. After considering the merits of a number of sites, including some disused airfields and other fields in the vicinity of the new towns being developed around London, it was decided that the now organization should have its headquarters at Ditton Park, near Datchet. In many ways this was a very suitable choice since various types of experimental work had been in progress in these grounds for many years past.

It was after the formation of the Radio Research Board in 1920 that a search was made for a suitable field in which to conduct some experiments on the variation of the direction of propagation of radio waves. As the first chairman of the Board was Admiral of the Fleet Sir Henry Jackson, it was perhaps natural to find that the requirements could be met in the grounds of the Admiralty Compass Observatory in Ditton Park. So a start was made with experiments in radio direction-finding, to which were added, in succession, a study of field strengths from long-wave or low-frequency transmitting stations, investigations in atmospheries, the establishment of an ionospheric observatory, and the study of the modes of propagation of waves of high and very high frequencies.

From 1933 onwards, the Radio Research Station was regarded as an outpost of the Radio Division of the National Physical Laboratory, and while this Division was formally terminated in July 1952, the 
association of some of the staff with the National Physical Laboratory has continued in a gradually attenuated form until the new building became ready for occupation a few months ago.

\section{Past Radio Research}

In looking back over the past thirty-five years or so, we find that the staff of this station, together with research workers at universities associated with the Radio Research Organization, have made great contributions towards fundamental knowledge of the propagation of radio waves at all frequeneies and under all conditions of transmission. A considerable series of publications described the results of the various investigations conducted under the auspices of the Radio Research Board before the Second World War. The work on direction-finding already mentioned was extended to cover a very wide range of frequencies and was applied to the location of the sources of atmospherics as well as of radio transmitters. The demonstration of the use of spaced aerial systems to give the highest attainable accuracy in direction and of the twin-channel amplifier with cathode ray tube presentation has formed the basis of industrial development and its practical application over the past twenty years. A radio sounding balloon was developed, which led up to the present method of sounding the atmosphere for meteorological purposes. In combination with a direction finder for following the course of the free balloons, the direction and speed of winds could be determined.

Intensive research was carried out on the factors which determine the variation of radio field-strength with distance from the transmitter; and the results obtained over a wide range of frequencies have formed the foundation from which has evolved much of the planning of communications, broadcast. ing and radio navigation services.

At the beginning of the International Geophysical Year, it is appropriate to refer to the Second International Polar Year of 1932-33, when radio was used for the first time as a tool for exploring the physical characteristics of the upper atmosphere. Under the auspices of the Radio Research Board an expedition, including members of the staff of the Station, went to Norway to investigate ionospheric conditions in northern latitudes. It was on their return that the need for regular soundings of the ionosphere became apparent, and there was established at Slough the first ionospheric observatory in the world. From a modest beginning with occasional soundings on special days, there has grown the organization existing to-day, in which a world network of one hundred. or more observatories record conditions in the ionosphere at every hour of the day and night. Automatic equipment developed at the Radio Research Station is used at more than twenty of these observatories, six of which are manned by personnel either belonging to, or trained at, the Station. This continuous worldwide study of the ionosphere has provided considerable knowledge used by engineers responsible for the planning and operation of long-distance radio communication and broadcasting services. These services are also assisted by the regular supply of forecasts of the transmission conditions prepared at the Station six months in advance.

All the work referred to so briefly above culminated a few years before the War in the demonstration of the detection at the ground of echoes of radio waves reflected from aircraft. Following this, a group of staff from the Station formed the nucleus of the team which developed the technique of radar up to the stage at which it was taken under the wing of the Air Ministry. This team had the advantage at the outset of being able to apply quickly to a practical objective the techniques of pulse transmission and echo reception, and of direction-finding in both horizontal and vertical planes, which had already been developed for the purpose of fundamental scientific research.

\section{Radio Research}

The present programme of the Radio Research Organization is designed to assist in the solution of some of the problems which confront the various users of radio waves and radio-frequency techniques, whether for civil, military or industrial purposes. The major portion of the work for the past few years has been concerned with meeting the needs of the communication, broadcasting and radio navigation services by studying the propagation of radio waves along the ground and through the lower and upper atmospheres, and taking account of the various types of disturbance caused by atmospherics of natural origin and by interference due to electrical equipment. Other portions of the programme include an investigation of the physical properties of certain materials, such as semiconductors and ferromagnetic compounds, which are of special interest in the radio field. The measurement of power and field-strength, particularly in the upper bands of radio frequency, is also the subject of study and development.

Measurements are being made of the speed with which radio waves travel over land and sea, and the results correlated with geological structure and ground conductivity. The effects on wave transmission of irregularities in the ground and the presence of natural or man-made obstacles, such as hills, trees and buildings, are studied with a view of determining, for example, the probable service area of new television stations at increasingly higher frequencies.

The transmission of very short waves to distances beyond the horizon is largely determined by the vertical gradient and regularity of temperature, pressure and humidity in the lower atmosphere or troposphere. A long-term investigation is in progress on the relationship between radio and meteorological conditions in order to obtain the information required in assessing the performance of communication, broadcasting and television services; and especially for the future planning of such services, including radio links, at wave-lengths from a few metres down to a few centimetres.

The Radio Research Station is responsible for the maintenance of six observatories, two in the United Kingdom and four on British territory overseas, which make a continuous study of the characteristics of the ionosphere by the vertical sounding technique. The results obtained at these observatories and at some seventy-five other's maintained by other countries are used in the preparation of forecasts of radio transmission conditions all over the world, six months in advance. These forecasts are used on a wide scale by organizations operating broadcasting, communication services and by air and marine navigation authorities.

The technique of sounding the ionosphere has recently been extended to points remote from the observing station by measuring the characteristics of echoes received by a combination of ionospheric 
reflexion and back-scattering from the ground at distances up to $10,000 \mathrm{~km}$. $(6,000 \mathrm{miles})$ or more. The study of the nature, time and direction of arrival of such echoes is greatly increasing our knowledge of the manner in which radio waves are transmitted to large distances around the world.

The scope of the various radio services is frequently restricted by the background of noise against which the signals have to be observed. Much of this noise is due to atmospheric disturbances arising in thunderstorms and lightning flashes. Measurements of the intensity of this noise are made in various parts of the world with a uniform type of apparatus designed at the Radio Research Station. The characteristics of this disturbing noise are also under continuous investigation in order to develop means of mitigating its effects. Other apparatus for locating the sources of these atmospheric disturbances has been developed and is used by the Meteorological Office to supply information on the position of storm centres for use in weather forecasting. An equipment for counting lightning flashes is under development in order to assist the meteorologist to supply information on the frequency and distribution of thunderstorms-information which is also required by the radio scientist.

Most of the apparatus required for these and similar investigations is of a highly specialized nature, and has been developed entirely at the Radio Research Station. In some cases, where the equipment is of interest to other users in Britain or abroad, a commercial firm has been assisted in reproducing it. Instances of such manufacture are the ionospheric recording equipment, which is entirely automatic in operation, the cathode ray direction finder for locating sources of atmospherics and the apparatus for measuring the strength of atmospheric noise on high and medium radio-frequencies.

In 1922, Admiral Sir Henry Jackson, chairman of the Radio Research Board, attended the first meeting of the International Scientific Radio Union (U.R.S.I.) in Brussels. In his report to the Board, he stated that all the suggestions which had been worked out in Britain as the basis of future radio research had been accepted internationaily. This was the beginning of an association which rapidly developed on an international basis between the staff of the Department of Scientific and Industrial Research employed on radio research and their contemporaries in other countries engaged on similar problems. Many of these problems have involved close collaboration in, for example, the provision of programmes of transmissions, and the standardization of measurements on the ionosphere and of the terminology used in connexion therewith. Sir Edward Appleton attended the next meeting in Washington of the International Scientific Radio Union, of which he was president during 1934-52, and members of the radio staff of the Department of Scientific and Industrial Research have attended all subsequent meetings of the Union, and played a prominent part in promoting international research in scientific radio. At the present time, the writer is a vice-president of the Union, and chairman of Commission II dealing with "Radio and the Troposphere".

In a corresponding manner, the director and staff of the Radio Research Station have for many years past worked in co-operation with the Post Office delegation on the more practical problems studied by the International Radio Consultative Committee
(C.C.I.R.), which is a technical advisory body of the International Telecommunications Union. Particularly in the field of radio wave propagation, much of the graphical and other results put forward by Britain have been adopted internationally as the basis for planning new radio communication and other services.

\section{International Geophysical Year}

The Radio Research Station is closely connected with the activities of the International Geophysical Year in the fields of the ionosphere and atmosphere. The observatories at Slough, Inverness, Singapore and Port Stanley are being provided with increased. staff and facilities for conducting intensive programmes of measurement of heights, critical frequencies, absorption and drift in the ionosphere on the Regular World Days and Special World Intervals associated with the International Geophysical Year. Corresponding observations will also be carried out by a group attached to the Royal Society's expedition to Halley Bay on the Antarctic continent. Measurements of the level, characteristics and direction of arrival of atmospheric noise will be made at Slough, Singapore and Ibadan, Nigeria, where in addition intensive ionospheric observations will be made in co-operation with this Department.

In addition to this direct measurement work, the Radio Research Station has been designated as one of the four world centres for ionospheric and atmospheric noise data. Under this scheme about one hundred observatories associated with the western European nations will send to the Station tabulated. and graphical results and also copies of the original ionograms. These will be exchanged with the other world data centres in the United States, U.S.S.R. and Japan, so that each centre will have a complete set of all the observational material obtained during the International Geophysical Year, and will hold this available for supply to research workers in any country in the region. The classification and indexing of the material will be co-ordinated by the secretariat of the International Geophysical Year in Brussels.

\section{Publications and Staff}

It has been evident for many years that the publication of papers and reports was not the only means by which the knowledge gained by those associated with the Radio Research Organization is to be made available to those anxious to apply this knowledge. A considerable dissemination is also achieved by the direct contact through committee or individual meetings. But over the years there have been demands for the loan or transfer of members of the staff to other organizations, where they become leaders of small groups or large departments as the case may be. The Radio Research Station has also been used both as a recruiting base and training ground for the staffs of the corresponding radio research organizations in Australia and New Zealand.

During the War, several members of the Department's staff served in succession as radio officers in the British Commonwealth Scientific Office in Washington, and several others have visited both the United States and Canada from time to time on special missions connected with research work of mutual interest to Britain and North America. More recently some members of the staff have been appointed to senior positions in government establishments and in industry in Britain and other 
countries. While these movements of staff may be somewhat disturbing to those left behind to continue the research programme, the demand for such experienced men must be regarded as a compliment, and a testimonial to the success of the Radio Research Station.

The scope for research in the field of telecommunications continues to expand, providing problems worthy of study by the ablest physicists and electrical engineers. Many of the techniques developed for the rapid communication of information are equally applicable to line or cable and to radio transmission : and there are many fruitful fields of research in which it is confidently expected that the new organization will play its part in giving direct assistance to trade and industry.

\section{THE NATIONAL PHYSICAL LABORATORY}

\section{OPEN DAYS}

HE National Physical Laboratory held two open days on May 22 and 23, instead of one as has been its practice for some years. More than two hundred and fifty exhibits, more than half of them new, were on view to 3,600 guests of the Laboratory who came from industry, the universities and government departments.

A problem of particular importance in the design of aircraft is that of instability in flight. The Aerodynamics Division has recently developed a general theory for wings oscillating at any frequency in a subsonic stream. A separate investigation of the aerodynamic forces on control surfaces at low speeds is in progress using the DEUCE high-speed digital computer which has been programmed to carry out the complex calculations. Experiments are under way to establish the theory and to investigate special cases, such as the transonic region, where the theory is inadequate. Equipment developed for measuring the oscillatory forces on model wings with trailingedge flaps was demonstrated. As the inertial forces are very large compared with the aerodynamic forces, they are balanced against spring reactions in a system excited at its natural frequency by an electrical feedback loop. The direct aerodynamic moments are derived from measurements of driving power and of the change in frequency due to the wind forces, while the lift forces are measured by capacity pick-ups supporting the oscillatory system. Oscillatory pitching and hinge moments have been measured in the subsonic range and the results agree well with theory.

Another aerodynamic oscillatory phenomenon is a type of control-surface oscillation called 'buzz'. Buzz has been experienced on some aircraft at speeds approaching that of sound, and can be so severe that failure of the control surface or its operating mechanism may occur. It is essentially an aerodynamically excited oscillation in a single degree of freedom, the flap vibrating with an angular motion about its hinge against the stiffness of its control circuit, usually with a frequency between 10 and $40 \mathrm{c} / \mathrm{s}$. An experimental apparatus to reproduce buzz and to study the flow conditions in which it occurs was demonstrated in one of the high-speed tunnels. Schlieren investigations have shown that at least one buzz phenomenon starts when separation of the flow at the foot of the shock wave on the upper surface of the aerofoil takes place. High-speed ciné films of the interaction between flow and flap motion have been taken to assist in this study : some of these were on show.

The Control Mechanisms and Electronics Division displayed the new automatic computing engine (ACE) at present under construction. The design of this machine is a result of the experience gained from the ACE pilot model during its four years computing service at the National Physical Laboratory, and from the engineered version of the pilot model, DEUCE, at present in service. ACE will be a much more powerful computing tool than its predecessors because of its increased speed, larger memory and other additional functional facilities. In a typical day's working it will average 20,000 three-address operations per second: its speed is estimated at eight times that of DEUCE. Its large memory store, $1 \frac{1}{2}$ million binary digits, will allow very complex problems, hitherto beyond the capabilities of computing machines, to be solved. The new ACE will soon be ready to execute its first test programmes.

The Division demonstrated a new digital plotting table. This has an accuracy of better than 0.01 in., and it plots at the speed of two points a second. It is a very simple design and embodies transistors and printed circuits. It is expected to satisfy an important need for a machine which will plot graphs from digital information on punched eards or punched paper tape.

The Electricity Division demonstrated how the National Physical Laboratory atomic clock is being used to check the drift rates of precision quartz clocks and the variation in the rate of rotation of the Earth. Compared with the atomic clock, the Earth gains in the northern hemisphere summer and loses in the winter, the maximum deviation being $\mathbf{4 0}$ milliseconds. Due to improvements in the electronics associated with the atomic clock, frequencies can now be determined with an accuracy of one part in $10^{10}$ in a measurement lasting only a few minutes. A new atomic clock designed to give even greater reliability, higher accuracy and increased simplicity of operation is under construction.

The most spectacular item on view was the new one-million volt testing transformer. This replaces three air-insulated transformers installed more than thirty years ago. It is a single unit rated at $700 \mathrm{kVA}$. designed to give a single phase output of one million volts when supplied at 1,200 volts. The winding is oil-immersed in a steel tank, the assembly weighing 55 tons. It is supported from earth on porcelain columns so that the tank can be connected to the centre point of the high-voltage winding - the columns can withstand half a million volts without flashover. The transformer is located in the open air, but the output can be fed into the main high-voltage laboratory through a porcelain wall-bushing $36 \mathrm{ft}$. long weighing 4 tons (Fig. 1).

The Light Division has collaborated with the Control Mechanisms and Electronics Division to develop a machine-tool monitor. The particular device demonstrated was a screw-cutting lathe controlled from a diffraction grating. A moiré 